\title{
Aufzeichnung: Willkommenskultur in der Radiologie
}

Willkommenskultur - die meisten denken bei diesem Begriff an die Einbindung von Menschen mit Migrationshintergrund in Alltag und Beruf. Aber Willkommenskultur beinhaltet auch, wie man neue Mitarbeiterinnen und Mitarbeiter generell in Kliniken und Praxen erfolgreich einbinden und halten kann. Ideen zur Verbesserung des gerade in Zeiten des Mangels an Ärztinnen und Ärzten essentiellen Onboarding-Prozesses wurden Anfang Juni im Webinar „Willkommenskultur in der Radiologie - geht das überhaupt?" auf dem 102. Deutschen Röntgenkongress debattiert, organisiert durch die interne Diversity@DRG-Kommission. Im Webinar debattiert wurde über Willkommenskultur in der Radiologie, im Gesundheitswesen allgemein und über Strukturen und Prozesse, die eine gute Will- kommenskultur ausmachen. Nun liegt eine Aufzeichnung des Webinars vor.

Reinschauen lohnt sich: Das Video finden Sie auf dem YouTube-Kanal der Deutschen Röntgengesellschaft. 